\title{
DETERMINATION OF THE AIRBORNE SOUND INSULATION OF A STRAW BALE PARTITION WALL
}

\author{
Jiř́ TESLÍK ${ }^{1, ~}{ }^{*}$, Radek FABIAN , Barbora HRUBÁ ${ }^{1}$ \\ ${ }^{1}$ VŠB - Technical University of Ostrava, Faculty of Civil Engineering, 17. listopadu 15/2172, 70833 \\ Ostrava - Poruba, Czech Republic. \\ corresponding author: jiri.teslik@vsb.cz
}

\section{Abstract}

This paper describes the results of a scientific project focused on determining of the Airborne Sound Insulation of a peripheral non-load bearing wall made of straw bales expressed by Weighted Sound Reduction Index. Weighted Sound Reduction Index was determined by measuring in the certified acoustic laboratory at the Faculty of Mechanical Engineering at Brno University of Technology. The measured structure of the straw wall was modified in combinations with various materials, so the results include a wide range of possible compositions of the wall. The key modification was application of plaster on both sides of the straw bale wall. This construction as is frequently done in actual straw houses. The additional measurements were performed on the straw wall with several variants of additional wall of slab materials. The airborne sound insulation value has been also measured in separate stages of the construction. Thus it is possible to compare and determinate the effect of the single layers on the airborne sound insulation.
\end{abstract}

\author{
Keywords: \\ Straw bale; \\ Airborne Sound Insulation; \\ Clay plaster; \\ Sound insulation; \\ Acoustic comfort.
}

\section{Introduction and overview of the current state}

The acoustics of the indoor environment inside buildings is often disregarded and underestimated in the construction industry. The acoustics of the indoor environment in buildings is not only about the quality of listening, but it is especially about the quiet environment inside the buildings in which people live. According to the study by the WHO (the World Health Organization), modern people spend up to $90 \%$ of time in the artificially created environment inside buildings [1]. The increased noise level inside buildings can cause health and mental problems. The most common consequence of the increased noise level is the reduction of the quality of living and working environment. Building structures as partitions, ceilings, external walls and roofs separate single interior and exterior spaces of the building. These structures must fulfil a number of requirements, including their acoustic parameters. The acoustics attributes of a building structure are expressed by the value of the airborne sound insulation $R_{w}$. This attribute describes the loss of sound power transmitted by the air through the construction. The strange noise is a noise which is transmitted to the protected area (the interior). The laboratory value of Airborne Sound Insulation $R_{w}$ of building materials and structures are determined on the basis of realized acoustic measurements. The Airborne Sound Insulation of straw structures has not been laboratory determined in the Czech Republic. For this reason, the measurement of a sample of a straw external wall was performed to determine the laboratory value of the airborne sound insulation. A few results of the acoustic parameters of the straw structures have been published in technical press. These results indicate that the $R_{w}$ value of straw bale external walls with plastering is in the range $43 \div 59.4 \mathrm{~dB}$ [2], [3]. Technical details of straw bale constructions on which the measurements were performed in sources are not quite clear.

\subsection{Laboratory and field Airborne Sound Insulation}

The values of the Airborne Sound Insulation measured on the building constructions built-in in a real buildings are generally lower than the values obtained by the measurement in the acoustic laboratory. The cause of the differences may be in a different implementation of construction on the building site compared to the construction in the laboratory. Sound also spreads by sideways (the paths outside measured structure) in the house. We distinguish the following ways of the sound 
spreading. Way $D_{\mathrm{d}}$ is direct, while the types of ways labelled $F_{\mathrm{f}}, F_{\mathrm{d}}$, and $D_{\mathrm{f}}$ are side paths of sound spreading (through the side bordering structures). The side paths of sound spreading are excluded during the measurement in the laboratory and these side paths are not taken into the account when the calculation of the airborne sound insulation is being done (Fig. 1).

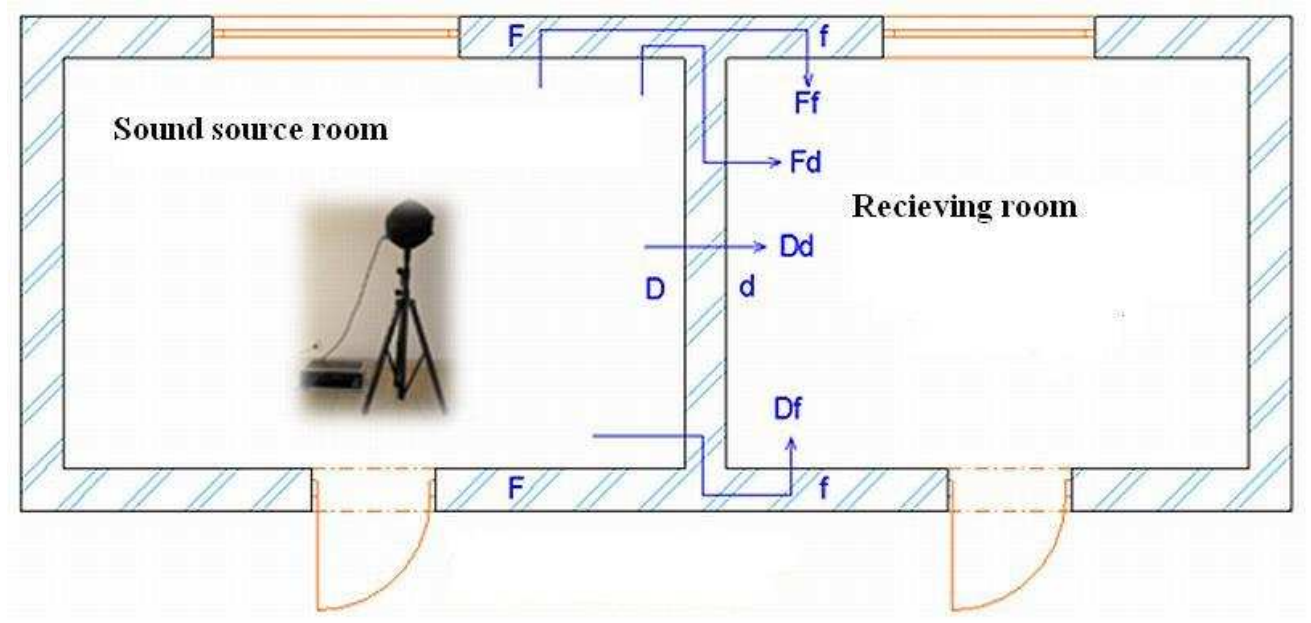

Fig. 1: Scheme of sound spreading ways between two rooms. By author.

We recognize:

- (laboratory) Weighted Sound Reduction Index $R_{\mathrm{w}}(\mathrm{dB})$ - it contains only way $D_{\mathrm{d}}$;

- field Weighted Sound Reduction Index $R_{\mathrm{w}}^{\prime}(\mathrm{dB})$ - labeled " $R$ prime" - contains all types of ways $F_{\mathrm{d}}, F_{\mathrm{f}}, D_{\mathrm{f}}$ without direct way $D_{\mathrm{d}}$.

The relationship between the two variables is:

$R^{\prime}{ }_{\mathrm{w}}=R_{\mathrm{w}}-k_{1}$,

where:

$k_{1} \quad$ is the correction which depends on the side ways of sound spreading:

$k_{1}=2 \mathrm{~dB} \quad$ basic value valid for all separating structures in solid masonry or prefabricated panel

buildings of traditional materials (bricks, concrete),

$k_{1}=2 \sim 5 \mathrm{~dB} \quad$ recommended values for the heavy separating structures in skeleton constructions (for example brick lining of the skeleton construction, etc.),

$k_{1}=4 \sim 8 \mathrm{~dB} \quad$ recommended values for the light separating structures in skeleton, steel or wooden constructions (slab components, plasterboard structures, wood ceilings, etc.).

The corrections are given in standard ČSN 730532 [4]. But the corrections are not determined for the structures made of straw. Field Sound Reduction Index $R^{\prime}[\mathrm{dB}]$ is the criterion for the evaluation of the structure, because only this criterion can be measured in the finished building. When receiving the data of the airborne sound insulation from the technical leaflets of the manufacturers of the separating structures it is necessary to distinguish between the measured data and the data stated by the manufacturer because the manufacturers sometimes state better laboratory values without further explanation.

The airborne sound insulation between rooms in buildings with a long-term stay of persons must fulfil the minimum required values of the sound insulation of separating structures in buildings given by national regulations. The values of the Weighted Sound Reduction Index of separating structures in EU are in range $R_{\mathrm{w}}=48 \sim 57 \mathrm{~dB}$ [5].

\subsection{Airborne Sound Insulation of single partitions and walls}

The Airborne Sound Insulation of single-layer building structures is the better, the heavier these structures are. The airborne sound insulation increases with the frequency of oscillation of the incident and transmitted sound. The airborne sound insulation is getting worse only in a specific case, when the effect of inertia of mass and the effect of flexural rigidity are mutually cancelled in that frequency domain. Flexural rigidity can affect the sound insulation in different ways. The effect of flexural rigidity 
is inconvenient for the single-layer structures, if the critical frequency of oscillation is in the range of $200 \mathrm{~Hz}$ to $2000 \mathrm{~Hz}$ (e.g. brick partitions with basis weight from $20 \mathrm{~kg} \cdot \mathrm{m}^{-2}$ to $100 \mathrm{~kg} \cdot \mathrm{m}^{-2}$ ). High flexural rigidity is convenient for thick walls, when the critical frequency of oscillation is lower than approx. 200 $\mathrm{Hz}$ (e.g. masonry constructions with basis weight min. $150 \mathrm{~kg} \cdot \mathrm{m}^{-2}$ ) [6].

The wall from straw bales with clay plaster is a simple wall from this point of view, because the plaster is applied directly on the straw bales by a contact method so there is no air gap in this structure.

\section{Acoustic measurements}

\subsection{The purpose of the measurement}

The aim of the measurement was to evaluate acoustic qualities - the laboratory Weighted Sound Reduction Index $R_{\mathrm{w}}$ of the proposed composition of the separating wall made of straw bales with different variants of surface finish. The subject of the measurement was the determination of laboratory airborne sound insulation according to ČSN EN ISO 10140-2 [7].

\subsection{Structural system of the measured straw wall}

The straw wall designed for the acoustic measurements was built in the structural system with a non-load-bearing straw (Fig. 2). This system was chosen because of greater popularity. Most of the straw buildings in the Czech Republic are built in a system with a non-load-bearing straw [2]. The construction of the sample of straw wall with dimensions $3 \mathrm{~m} \times 2 \mathrm{~m}$ contained four vertical sets of straw bales, see Fig. 3. Measured straw wall was $350 \mathrm{~mm}$ thick instead of the usual thickness of $450 \mathrm{~mm}$, because in the testing acoustic chamber can be built up sample only thickness of $350 \mathrm{~mm}$. The wooden load-bearing columns $160 \mathrm{~mm} \times 40 \mathrm{~mm}$ were inserted between each of the vertical sets of straw bales. The composition of the construction should correspond with the most frequently used structural system in practice called "two by four". The gaps between the vertical sets of straw bales were sealed by loose straw. The last step in the construction of the compact wall structure was various surface finishes. $U$-value of this construction type is $U=0.17$ to $0.20 \mathrm{~W} \cdot \mathrm{m}^{-2} \cdot \mathrm{K}^{-1}[8]$.

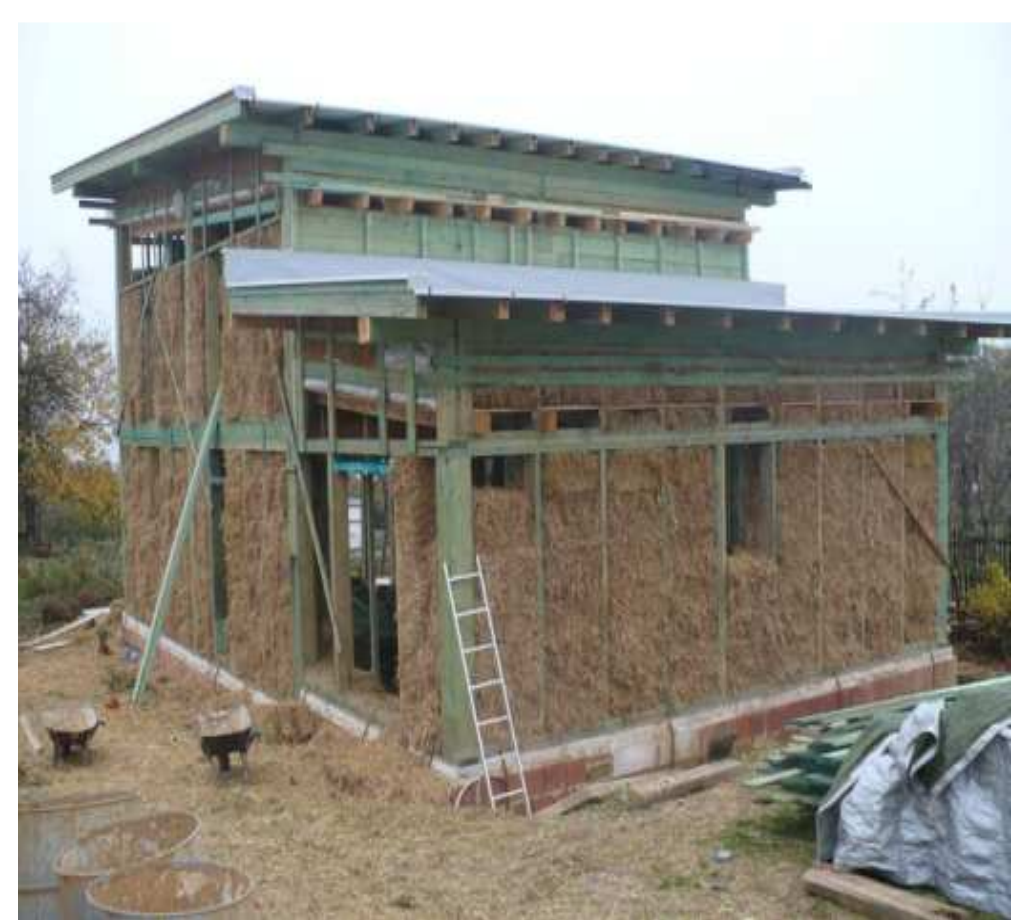

Fig. 2: Example of a straw house in a structural system with a non-load-bearing straw "two by four". By author. 


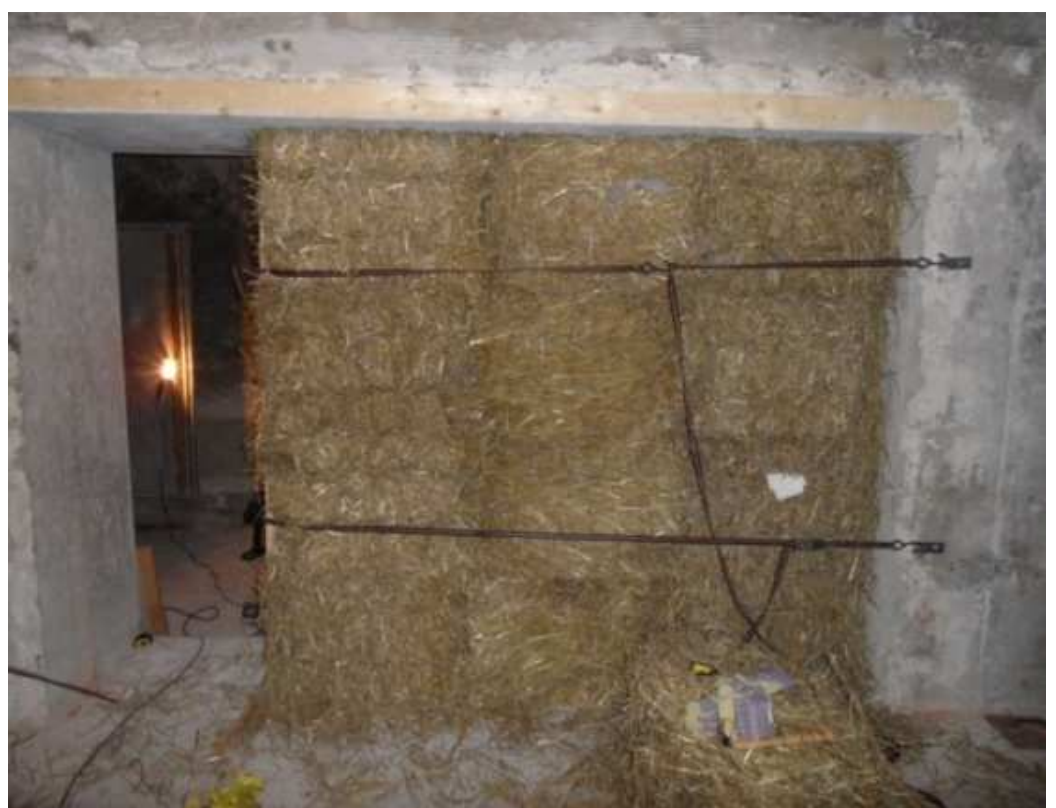

Fig. 3: Gradual assembly of the straw wall into the test hole in the acoustic laboratory chamber of Brno University of Technology. By author.

\subsection{Testing process of measurement}

The measurements were carried out in the sound chamber of the acoustic laboratory of the Faculty of Civil Engineering at Brno University of Technology. The acoustic chamber construction complies with ČSN EN ISO 10140-5 [7]. The tested sample is built between the chamber with the sound source and the chamber for the reception of sound. Steady sound with a continuous spectrum in the range from $100 \mathrm{~Hz}$ to $5000 \mathrm{~Hz}$ is excited in the chamber with the sound source. The mean value of the acoustic pressure (in $\mathrm{dB}$ ) is measured in both chambers. Airborne Sound Insulation $R$ is defined by the relation:

$$
R=L_{1}-L_{2}+10 \log S \cdot A^{-1}
$$

where:

$R$ - sound reduction index $(\mathrm{dB})$,

$L_{1}$ - mean value of acoustic pressure in the room with the sound source $(\mathrm{dB})$,

$L_{2}$ - mean value of acoustic pressure in the room for the reception of the sound (dB),

$S$ - area of the tested sample $\left(\mathrm{m}^{2}\right)$,

$A$ - the equivalent absorption area in the room for the reception of sound $\left(\mathrm{m}^{2}\right)$.

The size of equivalent absorption area is determined by reverberation time measured according to ČSN ENISO 3382-2 [9], using the Sabin's formula:

$A=(0.16 \cdot V) \cdot T^{1}$,

where:

$A$ - the equivalent absorption area in the room for the reception of sound $\left(\mathrm{m}^{2}\right)$,

$V$ - capacity of the room for the reception of sound $\left(\mathrm{m}^{3}\right)$,

$T$ - reverberation time in the room for the reception of sound (in seconds).

Numerical quantity $R_{\mathrm{w}}$ and factors of conforming with the spectrum $C, C_{\mathrm{tr}}$ are determined from the values of airborne sound insulation $R$ in one-third octave bands from 100 to $3150 \mathrm{~Hz}$ by the movement of baseline undulation according to ČSN EN ISO 717-1 [9]. 


\section{Composition, variants and results of measurements}

The acoustic measurements of the straw wall were performed within the project. The wall underwent several modifications. The principal aim was the specification of $R_{\mathrm{w}}$ of straw wall with double sided clay plaster; this structure is the most often used in straw constructions. Another variant was the straw wall with a clay plaster on the external side of the wall and an additional wall of slab materials. The structure of additional wall was of the supporting frame of $60 \mathrm{~mm} \times 40 \mathrm{~mm}$ wooden profiles. The selected slab materials were gradually mounted on supporting frame on the interior side. The acoustic measurements and the determination of the value of the Airborne Sound Insulation $R_{\mathrm{w}}$ $(\mathrm{dB})$ were carried out for each material variant. The results of the measurements are shown below.

\subsection{Straw wall without plasters}

The straw wall $350 \mathrm{~mm}$ thick without plasters was the first variant on which the acoustic measurement was carried out. The measurement should determine the acoustic insulation quality of the straw wall without plasters. The value of $R_{\mathrm{w}}$ of the straw wall without plastering was used to compare the level of the improvement of the acoustic qualities of other variants. The measurement showed that the straw wall has poor quality of Airborne Sound Insulation. The assumption that a certain springing and thereby increasing of noise attenuation occur in the structure of straw walls is not confirmed. The finishes of the straw structures have the decisive role as for the Airborne Sound Insulation which is based on the measured value of $R_{\mathrm{w}}=28 \mathrm{~dB}$. We assume that the increase in the thickness of the straw structure to the usual $450 \mathrm{~mm}$ would not improve significantly the value of airborne sound insulation.

The structure of the measured variant: straw bale, th. $350 \mathrm{~mm}$.

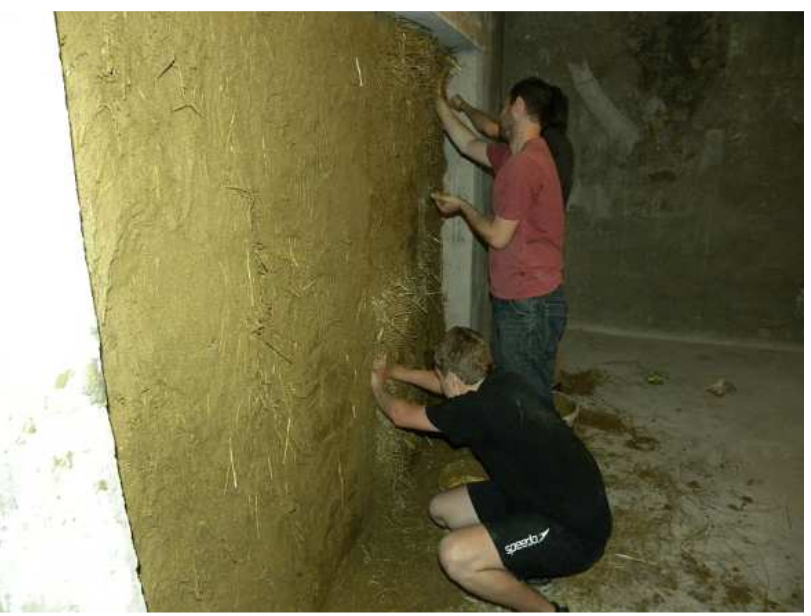

Fig. 4: Application of clay plaster on the straw bale wall surface. By author.

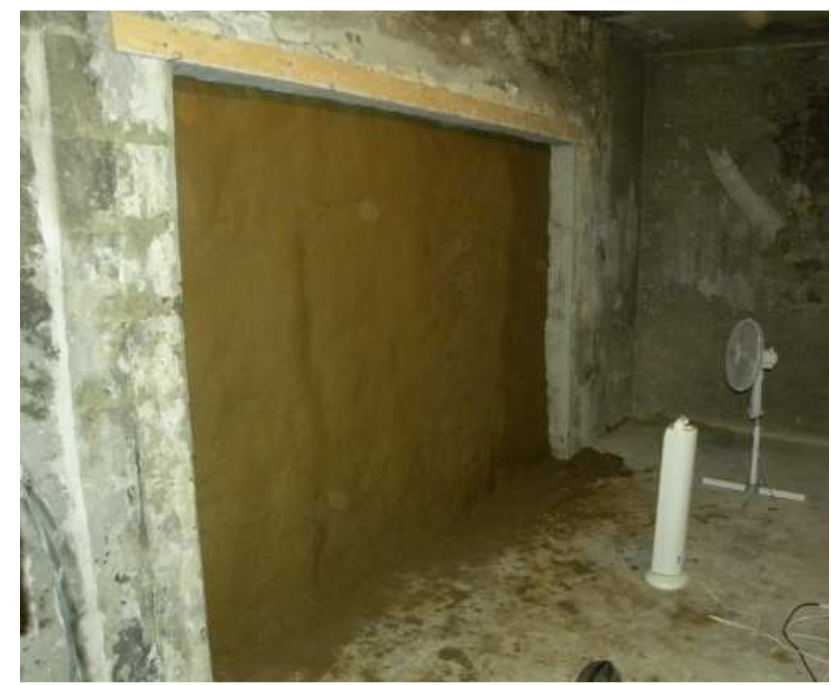

Fig. 5: Drying-out of external clay plaster before measurement. By author. 


\subsection{Straw wall with a wet clay plaster from one side}

The clay plaster was made on the exterior side of the straw wall after the completion of the structure of the straw wall. The clay plasters were applied in three layers. The first layer was the clay spraying applied directly on the straw bales to increase the adhesion of the base (Fig. 4). Spraying was done by fine-grained clay plaster Picas Econom. The core layer of roughcast Picas Econom was applied after the spraying had dried out. Picas Plasters are made of natural clay mixed with sand and chopped hemp. The final layer of plaster was applied on the core layer of plaster (Fig. 6). The average thickness of the plaster from the exterior side was $25 \mathrm{~mm}$. The acoustic measurement of the straw wall with moist plaster was carried out. The measured value of this variant was $R_{\mathrm{w}}=35 \mathrm{~dB}$ (Fig. 6). The wet clay plaster on one side of the straw wall increased the airborne sound insulation by $7 \mathrm{~dB}$.

The structure of the measured variant:

- clay plaster Picas Econom (wet), th. $20-30 \mathrm{~mm}$,

- straw bale wall, th. $350 \mathrm{~mm}$.

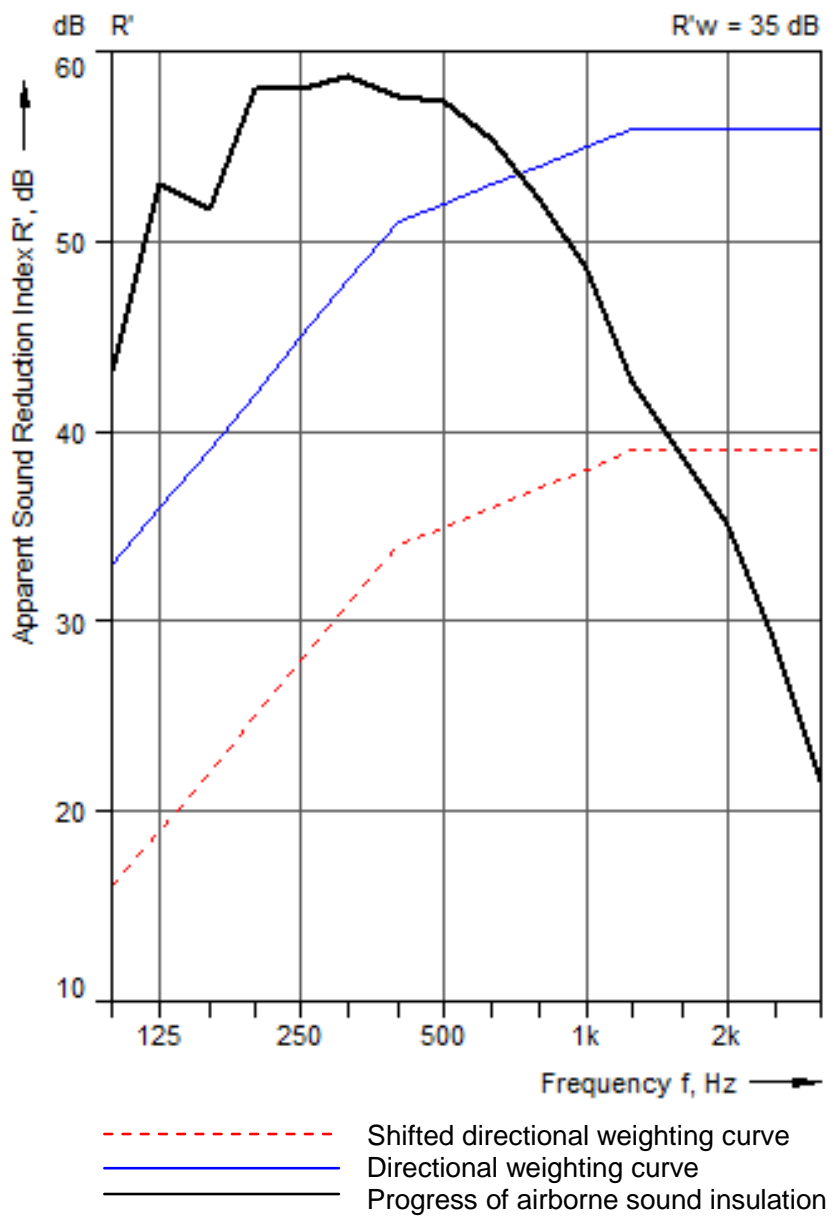

Fig. 6: Progress of airborne sound insulation in individual frequencies of straw wall with wet onesided clay plaster. 


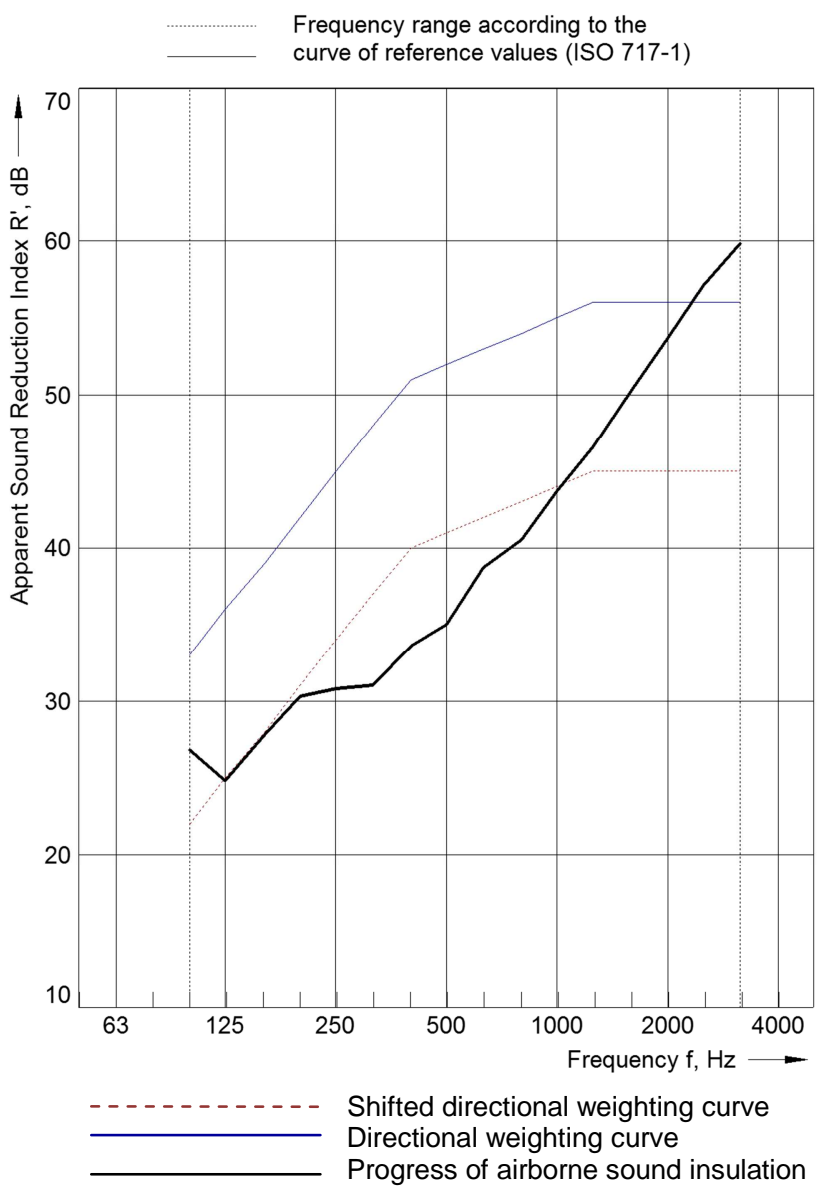

Fig. 7: Progress of airborne sound insulation in individual frequencies of straw wall with dry onesided clay plaster.

\subsection{Straw wall with dry clay plaster from one side}

The airborne sound insulation of the straw wall with one-side clay plaster was determined in this measurement. The clay plaster on the external side of the straw wall was dry (Fig. 5) unlike the variant described in 4.2. It is possible to compare the effect of the moisture on the value of $R_{\mathrm{w}}$. The assumption was that the variant with the moist plaster will have a greater $R_{\mathrm{w}}$ value than the variant with the dry plaster. The reason is the greater basic weight of the moist plaster. The measurement determined the value of the Weighted Sound Reduction Index of the straw wall with the dry plaster $R_{\mathrm{w}}=41 \mathrm{~dB}$. This value is $6 \mathrm{~dB}$ higher than the measured value at 3.2 , which was $R_{\mathrm{w}}=35 \mathrm{~dB}$. Progress of airborne sound insulation in individual frequencies is shown in Fig. 7.

The structure of the measured variant:

- clay plaster Picas Econom (dry), th. $20-30 \mathrm{~mm}$,

- straw bale wall, th. $350 \mathrm{~mm}$.

\subsection{Straw wall with a double-sided clay plaster}

The specification of $R_{w}$ value of a straw wall with double-side clay plaster was the main aim of the project. The surface of the straw bales was not suitable for the application of the clay plaster, because surface the quality of straw bales are not very good. A reed mat was attached to the straw wall for the improvement of the adhesion of the clay plaster. The clay plaster was applied on the mat in three layers (Fig. 9). The clay spraying of fine-grained clay plaster was the first layer. The other two layers were made of rough plaster Picas Econom with chopped hemp. The cracks in the link-up of the clay plaster and test aperture were sealed by clay plaster or modelling clay before the measurement. The average thickness of the clay interior plaster was $25 \mathrm{~mm}$. The acoustic measurement was performed after the interior clay plaster had dried out. The thicknesses of the clay plasters were not $40 \mathrm{~mm}$ as it is usual. The plasters dried out slowly due to high relative humidity of the indoor air in the acoustic chambers. Another layer of plaster would have to be applied to achieve $40 \mathrm{~mm}$ thickness of 
the plaster. This would require a longer time for drying out of the plasters. The resulting value $R_{w}$ of the straw wall with clay plasters is affected by thinner layers of plaster. Even though we measured the composition of the wall with a thinner layer of plaster, we achieved favourable values of $R_{w}$. The Weighted Sound Reduction Index value of this variant was $R_{\mathrm{w}}=54 \mathrm{~dB}$. Progress of airborne sound insulation in individual frequencies is shown in Fig. 8.

The structure of the measured variant:

- clay plaster Picas Econom, th. $20-30 \mathrm{~mm}$,

- straw bale wall, th. $350 \mathrm{~mm}$,

- clay plaster Picas Econom, th. $20-30 \mathrm{~mm}$.

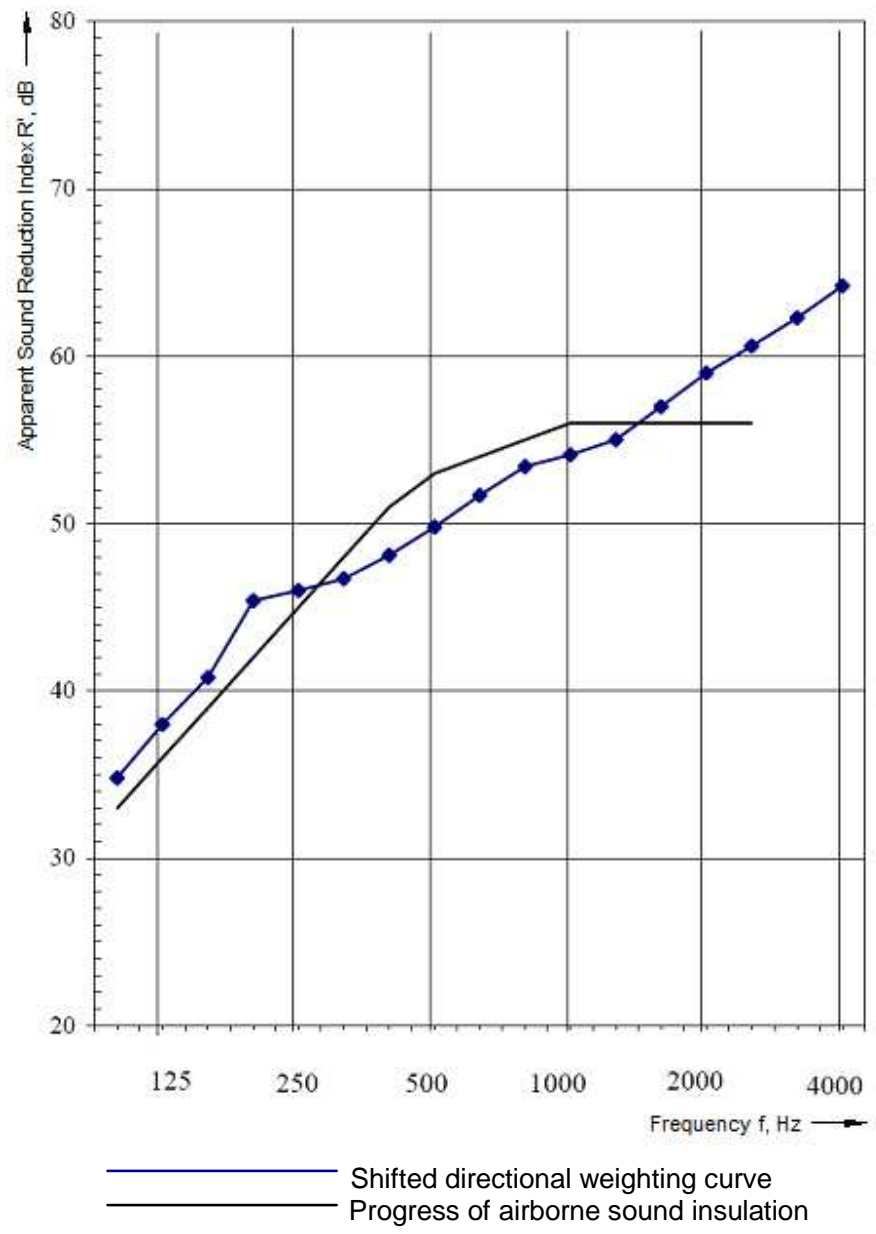

Fig. 8: Progress of the airborne sound insulation at the individual frequencies of straw wall with double-sided clay plaster. 


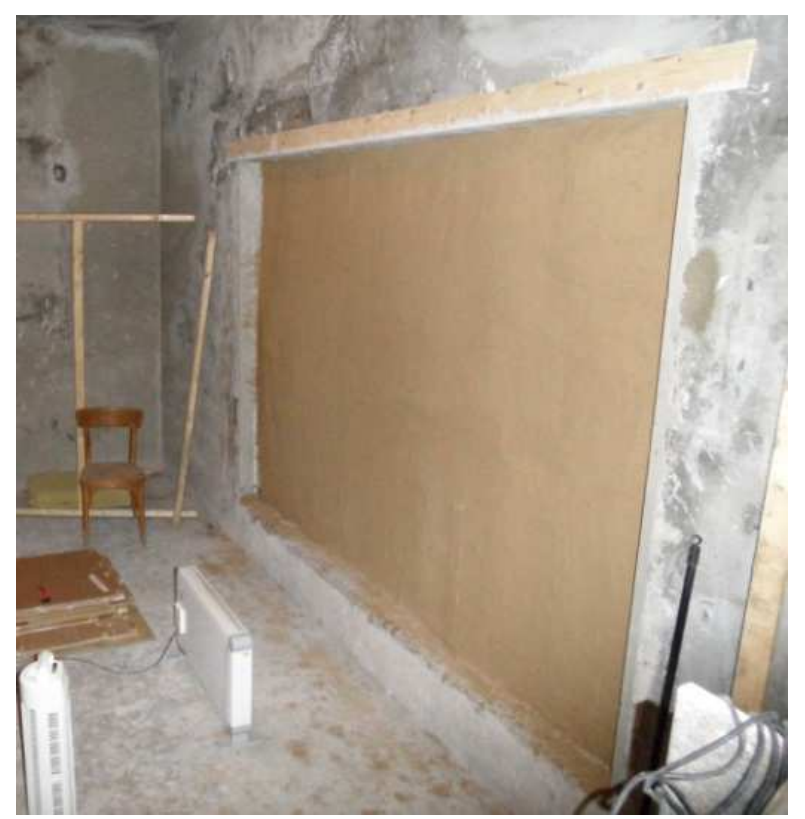

Fig. 9: View of the finished clay plaster on the interior side of the straw wall. By author.

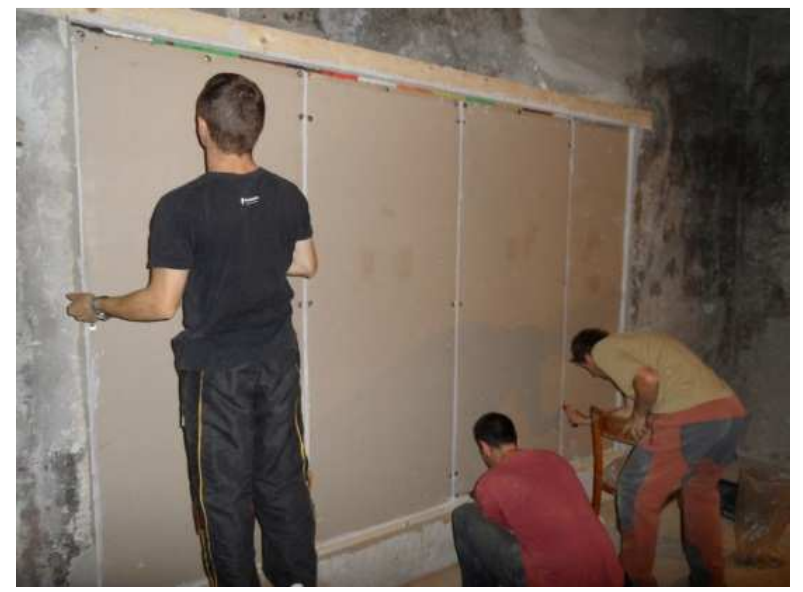

Fig. 10: Assembly and sealing of the gaps of additional Ecopanels wall. By author.

Table 1: Summary of the results of the acoustic measurements.

\begin{tabular}{|c|c|c|c|c|}
\hline Measured variant & $\begin{array}{l}\text { Density of material } \\
\qquad\left(\mathrm{kg} / \mathrm{m}^{3}\right)\end{array}$ & $\begin{array}{l}\text { Basic weight of } \\
\text { material } \\
\left(\mathrm{kg} / \mathrm{m}^{2}\right)\end{array}$ & $\begin{array}{l}\text { Weighted Sound } \\
\text { Reduction Index } \\
\qquad \boldsymbol{R}_{w}(\mathrm{~dB})\end{array}$ & $\begin{array}{c}\text { Improvement to the } \\
\text { sound insulation } \\
\Delta R_{\mathrm{w}}\end{array}$ \\
\hline Straw wall th . $350 \mathrm{~mm}$ & 90 & 31.5 & 28 & - \\
\hline $\begin{array}{l}\text { Clay plaster (wet) th. } 25 \mathrm{~mm} \\
\text { Straw wall th. } 350 \mathrm{~mm}\end{array}$ & $\begin{array}{c}2000 \\
90\end{array}$ & $\begin{array}{c}50 \\
31.5\end{array}$ & 35 & 8 \\
\hline $\begin{array}{l}\text { Clay plaster (dry) th. } 25 \mathrm{~mm} \\
\text { Straw wall th. } 350 \mathrm{~mm}\end{array}$ & $\begin{array}{c}1650 \\
90\end{array}$ & $\begin{array}{c}43 \\
31.5\end{array}$ & 42 & 14 \\
\hline $\begin{array}{l}\text { Clay plaster (dry) th. } 25 \mathrm{~mm} \\
\text { Straw wall th. } 350 \mathrm{~mm} \\
\text { Air gap th. } 40 \mathrm{~mm} \\
\text { Wolf PhoneStar Tri boards th. } 15 \mathrm{~mm}\end{array}$ & $\begin{array}{c}1650 \\
90 \\
- \\
1350\end{array}$ & $\begin{array}{c}43 \\
31.5 \\
- \\
14\end{array}$ & 57 & 29 \\
\hline $\begin{array}{l}\text { Clay plaster (dry) th. } 25 \mathrm{~mm} \\
\text { Straw wall th. } 350 \mathrm{~mm} \\
\text { Clay plaster (dry) th. } 25 \mathrm{~mm}\end{array}$ & $\begin{array}{c}1650 \\
90 \\
1650\end{array}$ & $\begin{array}{c}43 \\
31.5 \\
43\end{array}$ & 54 & 26 \\
\hline $\begin{array}{l}\text { Clay plaster (dry) th. } 25 \mathrm{~mm} \\
\text { Straw wall th. } 350 \mathrm{~mm} \\
\text { Air gap th. } 40 \mathrm{~mm} \\
\text { Ecopanel th. } 58 \mathrm{~mm}\end{array}$ & $\begin{array}{c}1650 \\
90 \\
- \\
379\end{array}$ & $\begin{array}{c}43 \\
31.5 \\
- \\
22\end{array}$ & 57 & 29 \\
\hline
\end{tabular}




\section{Conclusion}

The aim of conducted acoustic measurements was to determine which values of airborne sound insulation can reach the wall of straw bales. Measurements were carried out on a sample of wall where straw bales formed only thermal insulation filling of the supporting frame of wooden scantlings.

Acoustic measurements were performed in several phases of construction of the test sample of straw wall. This methodology proved to determine the influence of individual layers on value of laboratory airborne sound insulation of the sample. The first series of measurements were performed on a straw wall without surface treatment. Straw wall thickness of $350 \mathrm{~mm}$ reached the value of laboratory Weighted Sound Reduction Index only $R_{\mathrm{W}}=28 \mathrm{~dB}$. Subsequently straw wall was provided with surface finishes in several variants. This was the unilaterally made clay plaster thickness of approx. $25 \mathrm{~mm}$. In this variant, the acoustic measurements were made in the wet and dry clay plaster. The assumption was that structure with wet clay plaster will have a higher value of Weighted Sound Reduction Index due to the greater density of plaster with water. In this variant the measured value was $R_{\mathrm{w}}=35 \mathrm{~dB}$. After drying the clay plaster was carried another measurement and the measured value was $R_{\mathrm{w}}=42 \mathrm{~dB}$. A variant with dry clay plaster has better value of Weighted Sound Reduction Index by $7 \mathrm{~dB}$. Compared to variant of straw walls without plastering is improvement to the sound insulation $\Delta R_{w} 14 \mathrm{~dB}$. After this measurement were on the unplastered straw wall added board materials. The additional walls are made up of acoustic boards Wolf PhoneStar thickness $15 \mathrm{~mm}$ and boards made from pressed straw of the Ekopanel thickness $58 \mathrm{~mm}$ (Fig. 10). Both additional walls were mounted on a self-supporting grid of wooden lath $40 \mathrm{~mm} \times 60 \mathrm{~mm}$. Between the surface of the straw walls and the additional wall was air gap thickness $40 \mathrm{~mm}$. For both types of walls was measured laboratory value of Weighted Sound Reduction Index $R_{\mathrm{w}}=57 \mathrm{~dB}$. The last measured variation was straw wall with double-sided clay plaster. Clay plaster was applied at an average thickness of $25 \mathrm{~mm}$. After drying was measured laboratory value of Weighted Sound Reduction Index $R_{\mathrm{w}}=54 \mathrm{~dB}$. The results of individual measurements (Table 1) show that the largest share of the value of airborne sound insulation have finishes, no straw wall itself. It can be assumed, that neither the use of straw bales on higher density and thickness would not significantly improve the acoustic parameters of the straw walls without finishes.

\section{References}

[1] WHO Guidelines for Indoor Air Quality: Selected pollutants. The WHO European Centre for Environment and Health, Bonn Office, ISBN 978-92-890-0213-4, 2010.

[2] MINKE, G. - MAHLKE, F.: Strohballenbau. Hel. ISBN 978-80-86167-31-2, 2009.

[3] TESLÍK, J. - ZDRAŽILOVÁ, N. - VODIČKOVÁ, M.: Airtightness and acoustic properties of family house from straw. In: Advanced Materials Research, 860 - 863, pp. 1215 - 1218, 2014.

[4] ČSN 730532 Acoustics - Protection against noise in buildings and evaluation of acoustic properties of building elements - Requirements. Czech office for Standards, Metrology and Testing. Czech Republic, 2010.

[5] ZDRAZILOVA, N. - DONOVA, D. - WINKLER, J.: Degradation of airborne sound insulation of building structures due to built-in installations. In: International Multidisciplinary Scientific GeoConference Surveying Geology and Mining Ecology Management (SGEM), 2, pp. 75 - 82, 2015.

[6] ORAVEC, P.: Analysis of airborne sound insulation of partitions. Higher doctoral dissertations, VŠB-Technical University Ostrava, 137 p., ISBN 978-80-248-2539-7, 2011.

[7] ČSN EN ISO 10140 - 5 Acoustics - Laboratory measurement of sound insulation of building elements - Part 5: Requirements for test facilities and equipment Czech office for Standards, Metrology and Testing. Czech Republic, 2011.

[8] ĎURICA, P. - JURÁŠ, P. - PONECHAL, R. - ŠTAFFENOVÁ, D.: Long-time evaluation of thermaltechnical parameters of experimental wooden walls. In: CESB 2016 - Central Europe towards Sustainable Building 2016, Innovations for Sustainable Future, pp. 1063 - 1070, 2016.

[9] ČSN EN ISO 3382 - 2 Acoustics - Rating of sound insulation in buildings and of building elements - Part 1: Airborne sound insulation. Czech office for Standards, Metrology and Testing. Czech Republic, 2013.

[10]ČSN EN ISO 717 - 1 Acoustics - Rating of sound insulation in buildings and of building elements Part 1: Airborne sound insulation. Czech office for Standards, Metrology and Testing. Czech Republic, 2013. 